(Aus dem Kaiser Wilhelm-Institut für experimentelle Therapie, Berlin-Dahlem.)

\title{
Über die Verwendung von frischem, unabgebautem Toxin zur Herstellung und Prïfung von Diphtherieantitoxin.
}

\author{
Von
}

\section{A. v. Wassermann und M. Ficker.}

Die Frage nach der Wirksamkeit des Diphtherieheilserums, welche als im unbezweifelbar positiven Sinne beantwortet erschien, ist im Laufe der letzten Jahre wieder zur Erörterung gestellt worden. Es war hauptsächlich eine Arbeit von Bingel ${ }^{1}$ ), welche dieses Thema wieder aufrollte, indem dieser Autor bei Verwendung von normalem Pferdeserum im gleichen Prozentsatze Heilungen Diphtheriekranker erzielte wie mit antitoxischem Diphtherieheilserum. Diese Publikation Bingels rief eine rege Diskussion sowohl seitens der Kliniker wie auch von seiten der experimentellen Forscher hervor. Von ersteren waren es besonders $F^{\prime} e e r^{2}$ ), Karger ${ }^{3}$ u. a., von letzteren besonders Kolle $^{4}$ ) und seine Mitarbeiter, welche dazu Stellung nahmen, und die unzweifelhafte therapeutische Ubberlegenheit des antitoxinhaltigen Serums gegenüber dem sog. Leerserum betonten. Die dem Diphtherieheilserum skeptisch Gegenüberstehenden heben indessen stets hervor, daß die bei der experimentellen Meerschweinchendiphtherie mittels des heutigen Antitoxins erhobenen Befunde nicht in zwingender Form auf die menschliche Diphtherie übertragen werden dürfen. Ein Hauptargument bildet dabei der Einwand, daß es nicht sicher sei, ob die in der künstlichen Kultur allmählich gebildeten und nach Ablagerung dieser Kulturen zur Herstellung und Auswertung des Diphtherieheilserums benützten Toxine die gleichen seien wie diejenigen, welche bei der akuten menschlichen Diphtherie so rasch im Organismus entstehen. Tatsächlich ist

1) A. Bingel, Dtsch. Arch. f. klin. Med. 125, H. 4-6, S. 284. 1918.

2) E. Feer, Münch. med. Wochenschr. 1919, Nr. 13, 343.

3) P. Karger, Dtsch. med. Wochenschr. 1919, Nr. 22, S. 597.

4) W. Kolle und H. Schlossberger, Arbeit. a. d. Inst. f. Inf., Frankfurt a. M., 1919 , H. 8, S. 3.

Dieselben, Med. Klinik, 1919, Nr. 1, 4, 23, 24 u. 31.

Zeitschr. f. Hygiene. Bd, 96. 
es bei Diphtheric weit schwieriger als bei Tetanus, die vollkommene Identität des bei der Erkrankung im Menschen auftretenden Toxins und des Kulturtoxins nachzuweisen. Bei Tetanus ist dies, sowohl beim Kranken wie an der Leiche, im Blut häufig nachgewiesen worden ${ }^{1}$ ). Die Tiere, besonders weiße Mäuse, erkranken bei der Einspritzung mit Blut von an schwerem Tetanus Erkrankten oder von an Tetanus ohne Antitoxinbehandlung Gestorbenen unter den typischen tetanischen Erscheinungen, und diese lassen sich durch Zusatz von Serum eines mit Kulturtoxin vorbehandelten Tieres vollkommen neutralisieren. Damit ist die Identität des menschlichen Tetanustoxins mit dem Kulturtoxin zwingend nachgewiesen. Für Diphtherie liegen dagegen nur sehr wenige derartige Beobachtungen vor. Seit Einführung der Serumtherapie ist ein solcher Nachweis nur sehr selten zu führen, da kaum ein Arzt es mit seinem Gewissen vereinbaren wird, einen schweren Fall von Diphtherie - und nur um solche kann es sich für den Toxinnachweis im Blute handeln - ohne die Antitoxinbehandlung zu lassen. In der Zeit vor Einführung des Serums konnten derartige Untersuchungen bei geeigneten Fällen unternommen werden, und so haben Brieger und $A$. v. Wassermann einen Fall beschrieben ${ }^{2}$ ), bei dem es ihnen gelungen ist, in dem Blute der 8 Stunden post mortem obduzierten Leiche eines 9 jährigen post diphtheriam verstorbenen Knaben ein Toxin nachzuweisen, welches Meerschweinchen unter den typischen Erscheinungen der Kultur-Toxinvergiftung tötete. Aber, soweit aus der Literatur bekannt ist, blieb dieser Befund isoliert, und da damals das Diphtherieantitoxin noch unbekannt und deshalb der Identitätsnachweis dieses Giftes mit dem Kulturtoxin nicht absolut sicher nach unseren heutigen Anschauungen geführt werden konnte, ist auch dieser Fall nicht beweisend. Der obige Einwand wird also immer wieder erhoben, und wenn wir auf ihn näher eingehen, so ist festzustcllen, daß tatsächlich im Laufe der Zeit in der Gewinnung und Prüfung des Diphtherieserums gegenüber der Anfangszeit eine Änderung eingetreten ist. Die ersten einerseits von Behring und Wernicke, andererseits von Ehrlich und A. v. Wassermann dargestellten Diphtherieantitoxine, mit welchen die für die Serumtherapie entscheidenden Behandlungsversuche an der Heubnerschen Klinik, dem Baginskyschen Kaiser Friedrich-Kinderkrankenhaus und an den Städtischen Krankenhäusern in Berlin durchgeführt wurden, waren mit Toxinen gewonnen, die zumeist von frisch dem Kranken entnommenen Stämmen herrührten. Diese Kulturen waren also noch nicht allzu lange über künstliche Nährböden gegangen. Weiterhin benützte man zur Antitoxingewinnung - wenigstens in den Versuchen von Ehrlich und Wassermann - auch nicht sog. ,abgelagerte "

1) Lit. s. Kolle-Wassermann, Handbuch path. Mik. 2. Aufl. Bd. IV, S. 752.

2) Charité-Annalen. Bd. XVII.' 1892. 
Toxine, sondern, sobald ein Giftkolben das Vorhandensein von für Meerschweinchen hochwertigem Toxin ergab, was meistenteils nach 1-2 Wochen der Fall war, wurde dieses Toxin sofort zur Vorbehandlung des serumliefernden Tieres benützt. In dieser Hinsicht sind im Laufe der Zeit bei den meisten Serumherstellungsstätten Änderungen eingetreten. Diese bestehen zunächst darin, daß jede Fabrik über einige für die Toxingewinnung besonders geeignete Kulturen verfügt und nun ihr Toxin beinahe ausschließlich mit diesen herstellt. Als ein besonders hochwertiger Toxinproduzent hat sich ein von Park im New Yorker Gesundheitsamt isolierter Stamm erwiesen, und dieser ist daher auch stark verbreitet. Weiterhin haben die Arbeiten von Ehrlich über die Umwandlung eines Teiles des frischen Diphtherietoxins in unwirksame, bzw. schwächer und anders toxische Stoffe, wie die Toxoide und Toxone, dazu geführt, die Diphtherietoxine, ehe sie den Tieren zwecks Antitoxingewinnung injiziert werden, erst längere Zeit, unter Umständen monatelang, ,ablagern“ zu lassen. Während dieser Zeit soll das Diphtherietoxin gleichsam erst reifen, $d . h$. den Umwandlungsprozeß in Toxoide und Toxone bis zur erreichten Konstanz durchmachen. Das gleiche gilt für das Diphtherietoxin, mit welchem die Bestimmung des Gehaltes an Antitoxineinheiten im Serum bei der Kontrolle durchgeführt wird. Auch dieses Prüfungstoxin muß erst bis zur biologischen Konstanz abgelagert sein, ehe es zur prüfungstechnischen Verwendung gelangt. Von diesen Gesichtspunkten aus könnte man also den Einwendungen der Skeptiker nicht jede Berechtigung absprechen, da es immerhin denkbar ist, daß eine junge, ihrem natürlichen Nährboden aus dem kranken Menschen frisch entnommene Kultur beim Wachstum der crsten Tage ein biologisch sich anders verhaltendes. Toxin ergeben könnte, als es jahrelang über künstliche Nährböden gegangene Stämme liefern, besonders wenn die Toxinproduktion in Kulturen über Wochen ausgedehnt wird und das Toxin alsdann noch monatelang einem Abbau überlassen bleibt. Diese Einwände waren für uns Veranlassung, dieser Frage von neuem näherzutreten und zu untersuchen, ob nicht ein Serum, das mit „Frischgift" von Diphtheriebacillen hergestellt ist, im Tierversuch und späterhin auch klinisch vielleicht andere Resultate ergibt als ein solches, wie es nach den allgemein üblichen Herstellungsmethoden jetzt fast ausschließlich in den Handel gelangt. Wir beschlossen daher, Toxine aus frisch den verschiedensten Diphtheriekranken entnommenen Stämmen herzustellen und zwar nur 20-24 Stunden lang bebrütete Kulturen, bzw, deren Toxine zu verwenden. Bei diesem Gedankengang war dic Tatsache maßgebend, daß die Diphtherie in ihren bösartigsten toxischen Formen eine meist sehr akut verlaufende Infektion ist, und wir deshalb vor allem die Produkte gewinnen wollten, welche seitens der jugendlichsten Generationen der 
genannten Bakterienart produziert werden. Daß die Diphtheriebacillen in Kulturen schon nach kurzer Bebrütungszeit Toxin zu liefern vermögen, hatte bereits vor vielen Jahren $H$. Kossel' ${ }^{1}$ ) nachgewiesen. Für uns kam es aber weiter darauf an, festzustellen, ob es möglich ist, derartige ,Frischgifte " in genügender Menge von den verschiedensten Stämmen innerhalb 24 Stunden zu erhalten. Denn die Gifte mußten hochwertig sein, damit bei Behandlung größerer Tiere nicht das Antigenvolumen übermäßig gesteigert zu werden brauchte. Des weiteren mußte es gelingen, das „Frischgift" fortlaufend zu erhalten, da es im Immunisierungsplan liegen sollte, die beim Aufbewahren sich bildenden Abbauprodukte auszuschalten.

\section{I. Über die Gewinnung von Diphtheriefrischgiften.}

Wir möchten nun zunächst die technische Herstellung solcher Diphtheriefrischgifte, wie sie von dem einen von uns ( $M$. Ficker) befolgt wurde, hier mitteilen. Die Herstellung der Bouillon wich nur insofern von der üblichen $a b$, als das verwendete Fleisch verworfenen, meist perlsüchtigen Tieren entstammte, die Verarbeitung zu Fleischwasser konnte infolgedessen nicht mit dem frischen Fleisch erfolgen, sondern sie erfolgte für gewöhnlich 2-3 Tage nach dem Schlachten der Tiere. Da das Fleisch während dieser Zeit nicht im Kühlraum gelegen hatte, so reagierte die von ihm hergestellte Bouillon in der Regel schwach alkalisch. Im letzteren Falle wurde sie mit Milchsäure zunächst auf Lackmusneutralität gebracht. Reagierte sie sauer, so erhielt sie Natronlauge bis zum Lackmusneutralpunkt. Als Indicator diente Lackmustinktur; die Alkalisierung geschah dann durch Zugabe von $7 \mathrm{ccm}$ Normalnatronlauge auf den Liter lackmusneutraler Bouillon. Für alle folgenden Versuche wurden nur ganz frisch vom Menschen isolierte Diphtheriestämme benutzt. Von $\mathbf{5 7}$ frisch isolierten Stämmen erwiesen sich 16, also nahezu 28\% als Häutchenbildner. Dieser Prozentsatz ist zu niedrig, denn anfangs wurden alle Diphtheriestämme, die in der zweiten Generation auf Bouillon kein Häutchen zeigten, nicht weiter berücksichtigt. Später aber ließ sich beobachten, daß einzclne Stämme erst in der dritten oder in noch späteren Generationen Häutchen entwickelten, während in den ersten Generationen keine Andeutung davon vorhanden war. Die Häutchenkulturen wurden alle 8 Tage von Bouillon zu Bouillon übergeimpft und bewahrten so ihre Fähigkeit, Oberflächenkulturen zu bilden. Sollte ein Gift hergestellt werden, so wurde zunächst. von der Häutchenstammkultur ein frisches Bouillonröhrchen angelegt und hiervon nach 24 Stunden auf frische Röhrchen weitergeimpft. So ließ sich bei den meisten Häutchenbildnem erreichen, daß schon

1) H. Kossel, Zentralbl. f. Bakteriol. usw., 19, Nr. 25, S. 977. 1896. 
nach 24 Stunden die ganze Röhrchenoberfläche mit einer Haut bewachsen war.

Die 24 Stunden alte Bouillon wurde nun durch steriles Fließpapier vorfiltriert, sodann auf de Haën-Filter Nr. 310 gegeben und mit Wasserstrahlluftpumpe durchgesaugt. Die Prüfung des Filtrats geschah durch subcutane Verimpfung auf Meerschweinchen von $250 \mathrm{~g}$, Sterilitätsprüfung des Filtrats durch Verimpfung auf Löfflerserum und Bouillon sowohl vom Filtrat direkt wie nach Zentrifugieren.

Schon die ersten Versuche ergaben, daß sich unter den angewandten Bedingungen von 1 tägigen Diphtheriebouillonröhrchen gut wirksame Toxine gewinnen lassen, in denen beispielsweise $0,1 \mathrm{ccm}$ oder $0,05 \mathrm{ccm}$ die Meerschweinchen in 1-4 Tagen töteten. Es wurde nun versucht, eine Konzentrierung des Giftes dadurch zu erhalten, daß die hohe Schicht Nährbouillon in den Kulturgläsern vermindert und gleichzeitig eine möglichst große Oberfläche geboten wurde. Zunächst kamen an Stelle der üblichen Reagensgläser Spitzröhrchen von $13 \mathrm{~cm}$ Höhe mit der lichten Weite von $3,5 \mathrm{~cm}$ zur Verwendung. Die Verjüngung der Spitze begann bei $9 \mathrm{~cm}$ (von oben gemessen), noch zweckmäßiger erwiesen sich besondere Flachkölbchen, die von der weitesten Ausbauchung bis zur Unterlage eine möglichst geringe Entfernung haben und nicht wie die üblichen Rundkolben von der weitesten Stelle steil nach unten führen, sondern in spitzem Winkel abfallen. In der Hauptsache wurden 2 Größen von Flachkolben benutzt, erstens kleinere mit $14-16 \mathrm{ccm}$ Inhalt, deren weiteste Ausbauchung innen einen Durchmesser von ca. $6 \mathrm{~cm}$ hatte, zweitens größere mit $25-30 \mathrm{ccm}$ Inhalt mit $7,6 \mathrm{~cm}$ lichter Weite an der breitesten Stelle.

Während in einem gewöhnlichen Reagensglas mit $14 \mathrm{ccm}$ Inhalt die Flüssigkeit in einer Tiefe von $6^{1} / 2-7 \mathrm{~cm}$ steht und eine Oberfläche von $2 \mathrm{qcm}$ hat, hat in den Flachkölbchen bei der gleichen Flüssigkeitsmenge die Schicht an den tiefsten Stellen eine Höhe von 2,2, bei den größeren Kölbchen von 2,5-3 cm, die Oberfläche der Kultur in den kleineren Flachkölbchen beträgt über $28 \mathrm{qcm}$, in den größeren Kölbchen mit $25 \mathrm{ccm}$ Inhalt ca. $45 \mathrm{qcm}$.

Es treffen mithin auf $1 \mathrm{ccm}$ Flüssigkeit

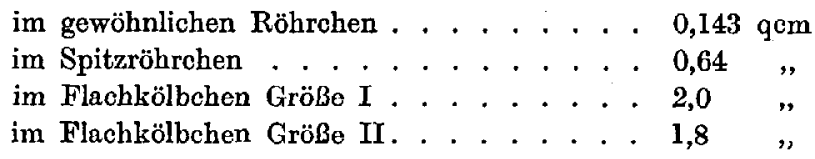

Wenn Giftbildung und Häutchenbildung im Zusammenhang stehen, so müssen in den Flachkölbchen sich stärkere Gifte erzielen lassen. Das ist in der Tat der Fall. 
Tabelle $I$.

I. Austitrierung von Toxin, Diphtheriestamm 6.

Vergleichender Versuch zwischen Röhrehen und flachen Kölbehen; Inhait je $14 \mathrm{ccm}$.

\begin{tabular}{c||c|c|c|c|c|c}
\hline \hline Meerschw. & & 1. Tag & 2. Tag. & 3. Tag & 4. Tag & 8. Tag \\
\hline \hline \multirow{2}{*}{413} & 0,05 T. & m. starker & s. starkes & starkes & starkes & starke \\
& Röhrchen & Strang & Infiltrat & Infiltrat & Infiltrat & Nekrose \\
412 & $0,025 \mathrm{~T}$. & geringes & starkes & starkes & starkes & starke \\
& Röhrchen & Infiltrat & Infiltrat & Infiltrat & Infiltrat & Nekrose \\
417 & $0,05 \mathrm{~T}$. & m. starker & s. starkes & tot & & \\
& Kölbchen & Strang & Infiltrat & & & \\
415 & 0,025 T. & m. starker & s. starkes & s. starkes & tot & \\
& Kölbchen & Strang & Infiltrat & Infiltrat & &
\end{tabular}

II.

Vergleichender Versuch zwischen Röhrchen und flachen Kölbchen, Inhalt $15 \mathrm{ccm}$.

\begin{tabular}{|c|c|c|c|c|c|}
\hline $437 \quad 0,05 \mathrm{~T}$. & o. B. & ınäßiges & geringes & o. B. & o. B. \\
\hline Röhrchen & & Infiltrat & Infiltrat & & \\
\hline $\begin{array}{l}\text { 0,025 T. } \\
\text { Röhrchen }\end{array}$ & o. B. & o. B. & o. B. & o. B. & o. B. \\
\hline $\begin{array}{c}0,05 \mathrm{~T} \text {. } \\
\text { Kölbchen }\end{array}$ & $\begin{array}{c}\text { starkes } \\
\text { Infiltrat }\end{array}$ & tot & & & \\
\hline $\begin{array}{l}0,025 \mathrm{~T} . \\
\text { Kölbchen }\end{array}$ & $\begin{array}{l}\text { mittelst. } \\
\text { Infiltrat }\end{array}$ & $\begin{array}{l}\text { starkes } \\
\text { Infiltrat }\end{array}$ & $\begin{array}{l}\text { starkes } \\
\text { Infiltrat }\end{array}$ & $\begin{array}{l}\text { starkes } \\
\text { Infiltrat }\end{array}$ & $\begin{array}{l}\text { geringes } \\
\text { Infiltrat }\end{array}$ \\
\hline $\begin{array}{c}0,01 \mathrm{~T} . \\
\text { Kölbchen }\end{array}$ & $\begin{array}{l}\text { s. geringes } \\
\text { Infiltrat }\end{array}$ & $\begin{array}{l}\text { m.starkes } \\
\text { Infiltrat }\end{array}$ & $\begin{array}{l}\text { mäßiges } \\
\text { Infiltrat }\end{array}$ & $\begin{array}{l}\text { m. starkes } \\
\text { Infiltrat }\end{array}$ & o. B. \\
\hline
\end{tabular}

III. Prüfung von.Toxin 41.

Vergleichender Versuch zwischen Röhrchen, kleinen Flachkolben und größeren Flachkolben.

\begin{tabular}{|c|c|c|c|c|c|}
\hline 958 & $\begin{array}{c}\text { 0,025 T. gr. } \\
\text { Flachkölbchen }\end{array}$ & $\begin{array}{l}\text { starkes } \\
\text { Infiltrat }\end{array}$ & - & 一 & tot \\
\hline 957 & $\begin{array}{c}0,01 \text { T. gr. } \\
\text { Flachkölbchen }\end{array}$ & $\begin{array}{l}\text { mäßiges } \\
\text { Infiltrat }\end{array}$ & - & - & $\begin{array}{l}\text { starkes } \\
\text { Infiltrat }\end{array}$ \\
\hline 956 & $\begin{array}{l}0,005 \text { T. gr. } \\
\text { Flachkölbchen }\end{array}$ & $\begin{array}{l}\text { mäliges } \\
\text { Infiltrat }\end{array}$ & - & - & $\begin{array}{l}\text { starkes } \\
\text { Infiltrat }\end{array}$ \\
\hline 961 & $\begin{array}{c}0,025 \text { T. kl. } \\
\text { Flachkölbchen }\end{array}$ & $\begin{array}{l}\text { starkes } \\
\text { Infiltrat }\end{array}$ & tot & & \\
\hline 960 & $\begin{array}{l}\text { 0,01 T. kl. } \\
\text { Flachkölbchen }\end{array}$ & $\begin{array}{l}\text { m. bis ger. } \\
\text { Infiltrat }\end{array}$ & - & tot & \\
\hline 959 & $\begin{array}{c}0,005 \mathrm{~T} . \mathrm{kl} . \\
\text { Flachkölbchen }\end{array}$ & $\begin{array}{l}\text { mäßiges } \\
\text { Infiltrat }\end{array}$ & - & tot & \\
\hline 964 & $\begin{array}{l}\text { 0,025 T. } \\
\text { Röhrchen }\end{array}$ & $\begin{array}{l}\text { m. starkes } \\
\text { Infiltrat }\end{array}$ & - & & $\begin{array}{l}\text { starkes } \\
\text { Infiltrat }\end{array}$ \\
\hline 963 & $\begin{array}{c}0,01 \mathrm{~T} . \\
\text { Röhrchen }\end{array}$ & $\begin{array}{l}\text { geringes } \\
\text { Infiltrat }\end{array}$ & - & & $\begin{array}{l}\text { m. starkes } \\
\text { Infiltrat }\end{array}$ \\
\hline 962 & $\begin{array}{l}0,005 \mathrm{~T} \text {. } \\
\text { Röhrchen }\end{array}$ & $\begin{array}{l}\text { s. geringes } \\
\text { Infiltrat }\end{array}$ & 一 & $\rightarrow$ & $\begin{array}{l}\text { mäßiges } \\
\text { Infiltrat }\end{array}$ \\
\hline
\end{tabular}


unabgebautem Toxin zur Herstellung und Prufung von Diphtherieantitoxin.

Die Versuche zeigen übereinstimmend, daß in den eigens konstruierten Flachkölbchen, in denen eine möglichst große Oberfläche den Häutchenbildnern Gelegenheit zur raschesten Ausbreitung bietet, die stärkere Konzentrierung des Diphtheriegiftes in dem relativ geringeren Nährflüssigkeitsvolumen erfolgt. Es fragt sich nun, ob die Bildung derartiger junger Gifte zu den Seltenheiten gehört, wie ja für die Giftgewinnung bei der Antitoxinherstellung nur ganz wenige Kulturen geeignet sind, oder ob sie einer größeren Anzahl von Stämmen zukommt und mit einer gewissen Konstanz erfolgt. Die folgende Tabelle zeigt, in welchen Dosen diese jungen Gifte für Meerschweinchen tödlich wirkten.

Tabelle II.

\begin{tabular}{|c|c|c|c|c|c|}
\hline $\begin{array}{l}\text { Stamm } \\
\text { Nr. }\end{array}$ & Datum & $\begin{array}{l}\text { Tödliche } \\
\text { Dosis }\end{array}$ & M. Gr. & $\begin{array}{l}\text { Tot in } \\
\text { Tagen }\end{array}$ & $\begin{array}{c}\text { Starkes Infiltrat } \\
\text { bei Dosis }\end{array}$ \\
\hline 4 & 4. T. 1919 & 0,05 & 250 & 4 & 一 \\
\hline 4 & 4. I. 1919 & 0,025 & 250 & 6 & $<0,01$ \\
\hline 5 & 27. XIT. 1918 & 0,05 & 400 & $4-5$ & 0,01 \\
\hline 5 & 6. V. 1919 & 0,025 & 250 & - & 0,01 \\
\hline 6 & 27. XII. 1918 & 0,025 & 250 & 4 & 0,01 \\
\hline 6 & 17. I. 1919 & 0,025 & 250 & 3 & $\ldots$ \\
\hline 6 & 18. I. 1919 & 0,01 & 250 & 4 & - \\
\hline 6 & 30. I. 1919 & 0,025 & 250 & 2 & - \\
\hline 6 & 18. II. 1919 & 0,025 & 250 & 4 & - \\
\hline 6 & 25. III. 1919 & 0,025 & 250 & 1 & - \\
\hline 6 & 12. IV. 1919 & 0,025 & 250 & 3 & - \\
\hline 6 & 29. IV. 1919 & 0,05 & 250 & 4 & $<0,01$ \\
\hline 6 & 3. VI. 1919 & - & - & 一 & 0,01 \\
\hline 8 & 8. I. 1919 & 0,2 & 400 & 4 & 0,1 \\
\hline 10 & 9. I. 1919 & $>0,2$ & 400 & - & 0,05 \\
\hline 11 & 17. I. 1919 & 0,025 & 250 & $4-5$ & $\begin{array}{l}<0,025 \\
>0,01\end{array}$ \\
\hline 37 & 6. V. 1919 & 0,025 & 250 & 3 & - \\
\hline 38 & 6. V. 1919 & 0,025 & 250 & 8 & - \\
\hline 38 & 20. V. 1919 & 0,025 & 250 & 4 & $<0,01$ \\
\hline 41 & 21. V. 1919 & 0,01 & 250 & 3 & -- \\
\hline 41 & 31. V. 1919 & 0,005 & 250 & 4 & $<0,0025$ \\
\hline 41 & 3. VI. 1919 & $>0,01$ & 300 & - & 0,005 \\
\hline 41 & 6. VI. 1919 & 0,005 & 250 & 3 & - \\
\hline 41 & 24. VIT. 1919 & 0,025 & 250 & 3 & - \\
\hline 46 & 13. V. 1919 & $>0,025$ & 250 & 一 & 0,025 \\
\hline 49 & 21. V. 1919 & 0,025 & 250 & 3 & $<0,01$ \\
\hline 50 & 21. V. 1919 & $>0,025$ & 250 & $\mathbf{3}$ & $>0,025$ \\
\hline 51 & 21. V. 1919 & 0,01 & 250 & 2 & $<0,025$ \\
\hline 58 & 27. IX. 1919 & $>0,025$ & 250 & - & 0,025 \\
\hline 59 & 27. IX. 1919 & $>0,025$ & 250 & - & 0,025 \\
\hline 60 & 27. IX. 1919 & 0,01 & 250 & 2 & $>0,01$ \\
\hline 62 & 13. I. 1920 & 0,025 & 250 & 3 & $<0,025$ \\
\hline
\end{tabular}


8 A. v. Wassermann und M. Ficker: Über die Verwendung von frischem,

Unter den angewandten Kulturbedingungen konnten, wie das Beispiel von Stamm 51 zeigt, durch längere Zeit hindurch die Giftwerte auf annähernd gleicher Höhe gehalten werden.

Tabelle III.

\begin{tabular}{c|l|l|l|l|l}
\hline $\begin{array}{c}\text { Stamm } \\
\text { Nr. }\end{array}$ & \multicolumn{1}{|c|}{ Datum } & $\begin{array}{c}\text { Tödliche } \\
\text { Dosis }\end{array}$ & M. Gr. & $\begin{array}{c}\text { Tot in } \\
\text { Tagen }\end{array}$ & $\begin{array}{c}\text { Starkes Infiltrat } \\
\text { bei Dosis }\end{array}$ \\
\hline 51 & 3. VI. 1919 & 0,005 & 250 & 4 & - \\
51 & 24. VI. 1919 & 0,0025 & 250 & 2 & - \\
51 & 9. VII. 1919 & 0,01 & 250 & 2 & 0,005 \\
51 & 16. VII. 1919 & 0.025 & 250 & 2 & 0,005 \\
51 & 24. VII. 1919 & 0,025 & 250 & 3 & - \\
51 & 28. VII. 1919 & 0,025 & 250 & 2 & 0,01 \\
51 & 19. VIII. 1919 & 0,01 & 250 & 3 & 0,005 \\
51 & 6. IX. 1919 & 0,025 & 250 & 2 & 0,005 \\
51 & 17. IX. 1919 & 0,025 & 250 & 2 & $<0,01$ \\
51 & 26. XI. 1919 & 0,01 & 250 & 2 & - \\
51 & 16. XII. 1919 & 0,01 & 250 & 2 & - \\
51 & 16. I. 1920 & 0,005 & 250 & 3 & - \\
51 & 28. IV. 1920 & 0,005 & 250 & 5 & - \\
\end{tabular}

Demnach ist es gelungen, von fast $1 / 3$ der frisch isolierten Diphtheriestämme junge 1 tägige Gifte zu gewinnen, die unter geeigneten Züchtungsbedingungen konstant gebildet werden und so konzentriert sind, daß ihrer Verwendung als Antigen zur Serumgewinnung nichts im Wege steht.

\section{II. Über die Gewinnung von Diphtherieantitoxin mit unabgebauten Frisch- toxinen.}

Mit diesen Toxinen wurden nun 2 Pferde vorbehandelt.

Das eine der Pferde (Schwarzer) wurde subcutan immunisiert. Die Immunisierung geschah in der üblichen Weise, indem zunächst Mischungen von Diphtherieserum und Frischtoxinen eingespritzt wurden, bis eine genügende Grundimmunität erreicht war, worauf Diphtherietoxin allein ohne Antitoxinzusatz in steigenden Dosen gegeben wurde. Das Diphtherietoxin stammte stets von 20-24stündigen Kulturen, wurde durch de Haënsche Membranfilter völlig keimfrei filtriert und an Meerschweinchen auf seine Toxizität geprüf. Ein zweites Pferd (Brauner) wurde in der gleichen Weise intravenös vorbehandelt. Die Vorbehandlung mit Frischtoxinen erfordert naturgemä $\beta$ einen weit größeren Zeit- und Arbeitsaufwand als diejenige mit konservierten abgelagerten Toxinen. Denn für jede Injektion müssen die betreffenden Toxinmengen zu dem betreffenden Tag frisch gewonnen werden. Da wir bei den Pferden zuletzt bis zu 1 Liter und darüber Injektionsdosis stiegen, läßt sich daraus bereits die technische Erschwerung gegenüber der gewöhnlichen Methode ermessen. Um Sicherheit darüber zu ge- 
winnen, daß die Toxine den nötigen Toxizitätsgrad besaßen, verfuhren wir in folgender Weise. Das einzuspritzende Toxin mußte unabgebaut, d. h. völlig frisch sein, es konnte deshalb der Ausfall der Toxizitätsprüfung an Meerschweinchen nicht abgewartet, sondern das Toxin mußte sofort den Pferden injiziert werden. Infolgedessen wurde gleich. zeitig damit an Meerschweinchen die Giftigkeitsprüfung ausgeführt und eine kleinere Menge des Toxins für etwaige weitere Impfung in zugeschmolzenen Röhrchen eingefroren aufbewahrt. Denn es zeigte sich, daß die ursprüngliche Giftigkeit beim Aufbewahren der Toxinlösung unter den üblichen Vorsichtsmaßregeln im Eisschrank sehr rasch abnahm. Auf diese Art und Weise waren wir also nie sicher, ob die betreffende Injektion bei dem Pferde hochwirksames Toxin enthielt. Dies ergab sich vielmehr erst aus dem nachträglichen Ausfalle der Titrierung an Meerschweinchen. Um aber möglichst gesichert zu sein, daß wir den Pferden nicht öfters unwirksame Toxinlösungen vergeblich einspritzten, verfuhren wir so, daß wir zunächst einen Stamm auf seine maximale Toxinproduktion innerhalb 24 Stunden ausprüften. Wir benutzten dann stets die gleiche Bouillon, die wir immer in großen Mengen herstellten, um ein gleichmäßiges Nährmedium zu besitzen. Auf diese Art und Weise gelang es, für die Immunisierung der Pferde fast stets genügend starkes Diphtherietoxin bei nur 24stündiger Bebrütung zu gewinnen. Die Stärke der Toxinlösung war wie oben gezeigt in den meisten Fällen so, daß $0,025 \mathrm{ccm}$ ein Meerschweinchen innerhalb 2-4 Tagen tötete. Die Immunisierungskurve der Pferde ergibt sich aus der beifolgenden Tabelle.

\section{Tabelle IV.}

Diphtherie-Pferd [Schwarzer $\left.\left.{ }^{1}\right)\right]$.

Immunisierungskurve.

Subcutane Impfung mit Frischtoxin.

6. VIII. $1919 \quad 1,0 \mathrm{ccm}$ Toxin Di 51 eingefroren und 0,00125 Di-Serum Frankfurt $1 / 2$ Stunde bei $37^{\circ}$

13. VIII. $1919 \quad 1,5 \mathrm{ccm}$ Toxin Di 51 und Serum Frankfurt wie am 6. VIII.

22. VIII. $19192,0, \quad, \quad " \quad$, (eingefroren vom 19. VIII. 1919)

29. VIII. $19195 \quad, \quad " \quad, \quad, \quad, \quad, \quad, \quad$, 19. VIII. 1919)

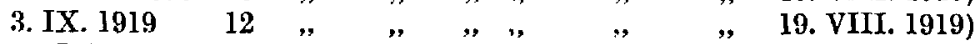

10. IX. $1919 \quad 25 \quad " \quad, \quad, \quad, \quad, \quad, \quad, \quad, \quad$ 6. IX. 1919)

17. IX. $191960 \quad " \quad, \quad, "$, (frisches Filtrat)

23. IX. $1919130 \quad " \quad, \quad, \quad, \quad, \quad$,

30. IX. $1919280 \quad, \quad, \quad, \quad, \quad, \quad, \quad$,

10. X. $1919560 \quad, \quad, \quad, \quad, \quad, \quad, \quad$,

17. X. $19191000 \quad " \quad " \quad, \quad, \quad, \quad, \quad$,

25. X. $19191300 \quad " \quad, \quad ", \quad, \quad$,

6. XI. 1919 Blutentnahme

1) Wir möchten nicht verfehlen, darauf hinzuweisen, daß das Tier bereits 16 Jahre alt war, so daß also bei einem jüngeren Tier vielleicht höhere Immunitätsgrade erzielt worden wären. 
10 A. v. Wassermann und M. Ficker: Über die Verwendung von frischem,

13. XI. $1919850 \mathrm{ccm}$ Di 51 (frisches Filtrat)

27. XI. $1919 \quad 1170, ",, \quad, \quad$,

9. XII. $1919 \quad 1000, ", \quad, \quad, \quad, \quad$,

16. XII. $1919 \quad 1000, ", \quad, \quad, \quad, \quad$,

23. XII. $19191000,, \quad, \quad, \quad, \quad$,

3. I. 1920

13. I. 1920

23. I. 1920

4. II. 1920

14. II. 1920

Blutentnahme

Serumversuch am 16. I. 1920.

$700 \mathrm{ccm}$ Toxin Di 51 (frisches Filtrat)

Blutentnahme (größere Menge)

$700 \mathrm{ccm}$ Toxin Di 51 (frisches Filtrat)

Blutentnahme

Serumversuch 16. II. und 24. II. 1920 . Heilversuch 4. III. und 6. III. 1920 25. II. $1920700 \mathrm{ccm}$ Toxin 51 (frisches Filtrat)

4. III. $1920 \quad 1000,, \quad, \quad, \quad, \quad$,

11. III. $19201200, \quad, \quad, \quad, \quad$,

23. III. 1920 Blutentnahme

25. III. $1920 \quad 600 \mathrm{ccm}$ Toxin 51

6. IV. 1920 Blutentnahme (größere Menge)

Serumversuch 24. IV. 1920. Heilversuch 30. IV. 1920

29. IV. 1920

10. V. 1920

$1000 \mathrm{ccm}$ Toxin 51

19. V. 1920

28. V. 1920

4. VI. 1920

11. VI. 1920

18. VI. 1920

28. VI. 1920

15. VII. 1920

22. VII. 1920

30. VII. 1920

7. VIII. 1920

Blutentnahme

$1100 \mathrm{ccm}$ Toxin 51 (frisches Filtrat)

1200 " , " , "

$1200 \quad, \quad$ " , " , " "

$1200 \quad, \quad, \quad, \quad$,

$1200, \quad, \quad, \quad, \quad$,

Blutentnahme

$1000 \mathrm{ccm}$ Toxin 51 (frisches Filtrat)

8. IX. 1920

$1100 \quad " \quad, \quad$ ",

$1100 \quad, \quad, \quad, \quad$,

$1100, \quad$ ", ", ",

$1000, " \quad ", "$ " "

28. X. 1920

5. XI. 1920

12. XI. 1920

20. XI. 1920

AbszeB, dann sehr langsame Abheilung

$300 \mathrm{ccm}$ Toxin 51 (frisches Filtrat)

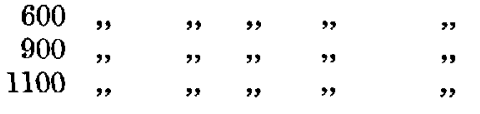

Das Serum unseres Pferdes wurde nun so ausgewertet, daß eine Antitoxineinheit mit 100 tatsächlich tödlichen Dosen des Frischtoxins gemischt wurde. Bekanntlich entspricht eine Antitoxineinheit derjenigen in $1 \mathrm{ccm}$ Diphtherieimmunserum enthaltenen Antitoxinmenge, welche imstande ist, 100 für Meerschweinchen von etwa $250 \mathrm{~g}$ innerhalb 3-4 Tagen tödliche Dosen Diphtherietoxin bei der direkten Mischung zu neutralisieren. Im Anfang der Diphtherieantitoxinperiode verfuhren Ehrlich und $A$. v. Wassermann so, daß in der Tat in der Prüfungsdosis diese 100 tödlichen Toxineinheiten enthalten waren. Es zeigte sich aber, daß es sehr schwer war, infolge der beim lagernden Diphtherietoxin vor sich gehenden Veränderungen die tödlichen Dosen in dem Prüfungsgifte konstant zu erhalten. Vielmehr tritt nach den bekannten Ehrlich 
schen Untersuchungen eine Umwandlung in unwirksame Modifikationen ein, so daß die Toxinprüfungsdose wohl noch ebensoviel Antitoxin zu binden vermag, aber der 100. Teil von ihr nicht mehr imstande ist, ein Meerschweinchen zu töten. Demgemä $\beta$ entspricht die heutige Prüfungsdose 100 bindenden, aber nicht mehr 100 tödlichen Einheiten. Es war also auch von Interesse festzustcllen, welche Differenz im Immunisierungs- und Heilwert zwischen einem Serum besteht, das nicht nur allein mit unabgebauten Frischtoxinen gewonnen war, sondern dessen Wertigkeit entsprechend den ersten Zeiten der Antitoxinperiode auch mit wirklich 100 tödlichen Dosen Toxins bestimmt wurde. Zu diesem Behufe werteten wir ein 24stündiges Frischtoxin, welches eingefroren und damit unveränderlich gehalten war, auf seine Dosis minima letalis aus. Entsprechend den Ehrlichschen Arbeiten wählten wir als Dosis minima certe efficax diejenige Menge, welche subcutan ein $250 \mathrm{~g}$ Meerschweinchen innerhalb 3-4 Tagen tötete. Gegen das 100 fache dieser Menge wurde alsdann das Serum unserer Pferde ausgeprüft. Im folgenden geben wir einen derartigen Versuch wieder.

16. I. $1920 . \quad$ Tabelle V. Serum-Mischversuch.

Di-Toxin 51 (1 täg. Filt. vom 6. I. 1920 eingefroren) + Di-Serum Schwarzer vom 3. I. 1920 und Di-Handelsserum Höchst (400 fach).

\begin{tabular}{|c|c|c|c|c|c|c|}
\hline $\begin{array}{l}\text { Meer- } \\
\text { sehw. } \\
\text { :ey0 }\end{array}$ & $\begin{array}{l}\text { Mischung } 1 / 2 \text { Std. bei } 37^{\circ} \\
\text { subcutan }\end{array}$ & 1. Tag & 2. Tag & B. Tag & 4. Tag & 8. Tag \\
\hline 20 & 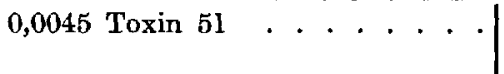 & $\begin{array}{l}\text { mäß. } \\
\text { Inf. }\end{array}$ & - & $\begin{array}{l}\text { z. st. } \\
\text { Inf. }\end{array}$ & $\begin{array}{l}\text { s. st. } \\
\text { Inf. }\end{array}$ & tot \\
\hline 21 & $0,005 \operatorname{Toxin} 51 \quad \cdots \cdots \cdot \cdots$ & mäß. & - & tot & & \\
\hline 22 & $\begin{array}{c}0,45 \text { Toxin } 51+0,0025 \text { Serum Höchst } \\
\text { (1 J. E.) . . . . . . . . }\end{array}$ & o. B. & - & o. B. & o. B. & o. B. \\
\hline 23 & 0,5 Toxin $51+0,0025$ Serum Höchst & o. B. & - & o. B. & o. B. & o. $\mathbf{B}$. \\
\hline 24 & 0,45 Toxin $51+0,01$ Ser. Sehwarzer & o. B. & - & o. B. & o. B. & o. B. \\
\hline 25 & 0,5 Toxin $51+0,01$ Ser. Schwarzer & o. B. & - & o. B. & o. B. & o. B. \\
\hline 26 & 0,45 Toxin $51+0,005$ Ser. Schwarzer & $\begin{array}{l}\text { z. st. } \\
\text { Inf. }\end{array}$ & tot & & & \\
\hline 27 & 0,5 Toxin $51+0.005$ Ser. Schwarzer & o. B. & - & o. $B$. & o. B. & o. B. \\
\hline
\end{tabular}

Wegen des paradoxen Ausfalls des Versuchs bei 'Tier 26 wurde folgender Ergänzungsversuch angestellt:

21. 1. 1920. Ergänzung zum Di-Versuch vom 16. I. 1920.

Dasselbe Toxin 51 (eingefroren) und Diphtherieserum Schwarzer.

\begin{tabular}{|c|c|c|c|c|c|}
\hline $\begin{array}{l}\text { Meer- } \\
\text { schw. } \\
2: 00 \mathrm{~g}\end{array}$ & $\begin{array}{l}1 / 2 \text { Std. bei } 37^{\circ} \\
\text { subcutan }\end{array}$ & 1. Tag & 2. Tag & 3. Tag & 6. Tag \\
\hline 33 & 0,0045 Toxin $51 \quad \ldots \ldots \ldots$ & $\begin{array}{l}\text { mäß. } \\
\text { Inf. }\end{array}$ & $\begin{array}{l}\text { s. st. } \\
\text { Inf. }\end{array}$ & $\begin{array}{l}\text { s. st. } \\
\text { Tnf kr. }\end{array}$ & tot \\
\hline $\begin{array}{l}34 \\
35\end{array}$ & $\begin{array}{l}0,45 \text { Toxin } 51+0,0025 \text { Serum Schwarzer } \\
0,45 \text { Toxin } 51+0,005 \text { Serum Schwarzer. }\end{array}$ & $\begin{array}{l}\text { o. } \mathrm{B} \text {. } \\
\text { o. } \mathrm{B}\end{array}$ & $\begin{array}{l}\text { o. B. } \\
\text { o B. }\end{array}$ & $\begin{array}{l}\text { o. B. } \\
\text { o. B. }\end{array}$ & $\begin{array}{l}\text { o. B. } \\
\text { o. B. }\end{array}$ \\
\hline
\end{tabular}


12 A. v. Wassermann und M. Ficker: Über die Verwendung von frischem,

Aus der vorstehenden Tabelle ersehen wir, daß das Serum (Schwarzer) in der Menge von 0,0025 gegen tatsächlich 100 tödliche Dosen des Frischtoxins schützte, es also sicherlich gegenüber diesem Toxin als 400 fach zu bezeichnen war. Wir haben dann das Pferd mit Frischtoxin weiterbehandelt und sind bei dem subcutan behandelten Tier (Schwarzer) bis auf 500 fachen Wert gegenüber 100 tödlichen Dosen Frischtoxin gelangt, während das intravenös behandelte Pferd, wie aus der folgenden Tabelle hervorgeht, in derselben Zeit kaum 100 fach war.

Tabelle. VI.

16. II. 1920.

Serum-Mischversuch

Di-Toxin 51 (l tägiges Filtrat vom 4. IJ. 1920 eingefroren)

+ Diphtherieserum Schwarzer (subc. Pferd), Serum vom 14. II. 1920

+ Diphtherieserum Brauner ((intravenöses Pferd)

\begin{tabular}{|c|c|c|c|c|c|c|}
\hline $\begin{array}{l}\text { Meer- } \\
\text { sehw. } \\
220 \text { bis } \\
230 \mathrm{~g}\end{array}$ & $\begin{array}{l}\text { Mischung } 1 / 2 \text { Std. bei } 37^{\circ} \\
\text { subeutan }\end{array}$ & 1. Tag & 2. Tag & 3. Tag & 4. Tag & E. Tag \\
\hline 387 & 0,006 Toxin 51 $\quad \ldots \ldots \ldots$ & $\begin{array}{l}\text { mäß. } \\
\text { Inf. }\end{array}$ & $\begin{array}{l}\text { m. st. } \\
\text { Inf. }\end{array}$ & - & $\begin{array}{l}\text { s. st. } \\
\text { Inf. }\end{array}$ & tot \\
\hline 392 & 0,6 Toxin $51+0,015$ Ser. Schwarzer & st. Inf. & st. Inf. & tot & & \\
\hline $\mathbf{3 9 3}$ & 0,6 Toxin $51+0,002$ Ser. Schwarzer & o. B. & o. B. & o. B. & o. B. & o. B. \\
\hline 394 & 0,6 Toxin $51+0,0025$ Ser. Schwarz. & o. B. & o. B. & o. B. & o. B. & o. B. \\
\hline 398 & 0,6 Toxin $51+0.01$ Ser. Brauner . & m. Inf. & tot & & & \\
\hline 399 & 0,6 Toxin $51+0,1$ Ser. Brauner . & o $\mathrm{B}$. & o. B. & o. B. & o. B. & o. B. \\
\hline
\end{tabular}

19. II. 1920. Ergänzung zum Serumversuch vom 16. II. 1920.

Dasselbe Toxin 51 vom 4. II. 1920 und Di-Serum Schwarzer vom 14. II. 1920.

\begin{tabular}{|c|c|c|c|c|c|c|}
\hline $\begin{array}{l}\text { Meer- } \\
\text { sehw. } \\
210 \mathrm{~g}\end{array}$ & $\begin{array}{l}\text { Misehung } 1 / 2 \text { Std. bei } 37^{\circ} \\
\text { subcutan }\end{array}$ & 1. Tag & 2. Tag & 3. Tag & 4. $\mathrm{Tag}$ & 5. Tag \\
\hline 671 & 0,007 Toxin 51 . & $\begin{array}{l}\text { ger. } \\
\text { Inf. }\end{array}$ & tot & & & \\
\hline $\begin{array}{l}942 \\
947\end{array}$ & $\begin{array}{l}0,7 \text { Toxin } 51+0,002 \text { Ser. Schwarzer } \\
0,7 \text { Toxin } 51+0,0025 \text { Ser. Schwarz. }\end{array}$ & $\begin{array}{l}\text { o. B. } \\
\text { o. B. }\end{array}$ & $\begin{array}{l}\text { o } B . \\
\text { o. B. }\end{array}$ & $\begin{array}{l}\text { o. B. } \\
\text { o. B. }\end{array}$ & $\begin{array}{l}\text { o. B. } \\
\text { o. B. }\end{array}$ & $\begin{array}{l}\text { o. B. } \\
\text { o. B. }\end{array}$ \\
\hline
\end{tabular}

Die nächste interessante Frage war nun, wie sich das mit abgebautem Toxin hergestellte, im Handel befindliche Diphtherieserum bei der Ausprüfung gegenüber den 100 Dosen unabgebauten Frischgiftes und auf der anderen Seite, unser mit Frischgift hergestelltes Diphtherieserum gegenüber dem abgebauten Standardtoxin, wie es im Institut für experimentelle Therapie in Frankfurt a. M. verwendet wird, verhält. Darüber geben die folgenden Tabellen Aufschluß.

Aus den Tabellen ergibt sich folgendes Resultat: Das mit abgebautem Toxin hergestellte, aus dem Handel bezogene 400 fache Diphtherieserum Höchst schützte in der Menge von $0,0025 \mathrm{cem}, \mathrm{d}$. h. in der 400 fachen Verdünnung gegen 100 tödliche Dosen Frischgift. - Die Untersuchung des mit Frischgift hergestellten Serums Schwarzer, welches bei der 
unabgebautem Toxin zur Herstellung und Prufung von Diphtherieantitoxin.

Tabelle VII.

29. XII. 1919.

S'rum-Mischersurh.

Toxin Di 51 (eingefroren vom 16. XII. 1920) + Di-Handelsserum Höchst (400fach).

\begin{tabular}{|c|c|c|c|c|c|}
\hline $\begin{array}{l}\text { Meer- } \\
\text { schws. } \\
2 \mathrm{Bg} \mathrm{g}\end{array}$ & $\begin{array}{c}\text { Mischung } 1 / 2 \text { Std. bei } 87^{\circ} \text {, } \\
\text { subcutan }\end{array}$ & 1. Tag & 2. Tag & B. Tag & 4. Tag \\
\hline 485 & 0,004 Toxin 51 & m. Inf. & - & tot & \\
\hline 486 & 0,005 Toxin 51 . . . . & m. Int. & - & tot & \\
\hline 487 & 0,006 Toxin $51 \ldots$ & m. Inf. & st. Inf. & tot & \\
\hline 488 & 0,008 Toxin $51 \ldots$ & ger. Inf. & tot & & \\
\hline 489 & 0,4 Toxin + 0,0025 Serum Höchst & o. $B$. & o. B. & o. B. & o. B. \\
\hline 490 & 0,5 Toxin $+0,0025$ Serum Höchst... & o. B. & ger. Inf. & tot & \\
\hline 491 & 0,6 Toxin $+0,0025$ Serum Höchst . . & ger. Inf. & m. Inf. & tot & \\
\hline 492 & 0,8 Toxin $+0,0025$ Serum Höchst . & ger. Inf. & tot & & \\
\hline
\end{tabular}

24. II. 1920.

Serum-Mischversuch.

Di-Toxin Frankfurt vom 29. I. $1920+$ Di-Serum Schwarzer vom 14. II. 1920 und

Di-Handelsserum Höchst (400 fach)

\begin{tabular}{|c|c|c|c|c|c|}
\hline $\begin{array}{l}\text { Meer- } \\
\text { schw: } \\
200 \mathrm{big} \\
220 \mathrm{~g}\end{array}$ & $\begin{array}{c}\text { Mischung } 1 / 2 \text { Std. bei } 37^{\circ} \text {, } \\
\text { subcutan }\end{array}$ & 1. Tag & 2. Tag & 3. Tag & 4. Tag \\
\hline 479 & 0,13 Toxin Frankfurt . . . . . . . . & $\begin{array}{l}\text { m. st } \\
\text { Inf. } \\
\text { tot } 3^{\text {h }}\end{array}$ & & & \\
\hline 496 & $\begin{array}{l}0,13 \text { Toxin Frankfurt }+4 \text { ccm Scruin } \\
\text { Schwarzer }(1: 1600) . \ldots . . .\end{array}$ & tot & & & \\
\hline 755 & $\begin{array}{l}\text { 0,13 Toxin Frankfurt }+4 \mathrm{ccm} \text { Serum } \\
\text { Schwarzer }(1: 1200) . . . .\end{array}$ & o. B. & o. B. & o. B. & o. B. \\
\hline 85 & $\begin{array}{l}\text { 0,13 Toxin Frankfurt }+4 \mathrm{ccm} \text { Serum } \\
\text { Schwarzer }(1: 1000) \cdot \cdot \cdot \cdot \cdot \cdot \cdot \cdot \cdot \cdot \\
0,13 \text { Toxin Frankfurt }+4 \text { ccm Senim }\end{array}$ & o. B. & o. B. & o. $\mathbf{B}$. & o. $B$. \\
\hline
\end{tabular}

Ausprüfung gegen Frischtoxin sich als über 500fach erwiesen hatte, zeigte sich bei der Prüfung mit dem abgebauten Frankfurter Standardgift als nicht so stark, indem es diesem Gift gegenüber schwächer als das Höchster Serum war. Denn die Dose 400 fach neutralisierte dieses Gift nicht; erst 300 fach zugemischt war es imstande, diese offizielle staatliche Prüfungsdose vollkommen zu neutralisieren. - Daraus geht also jedenfalls das mit Sicherheit hervor, da $\beta$ die Prüfung, wie sie im Frankfurter Institut durchgeführt wird, im Diphtherieserum keine Antitoxinkomponente außer acht läßt, welche etwa im Frischtoxin enthalten und im abgelagerten Toxin verschwunden sein könnte. Sie ist also keinesfalls einer Prüfung mit Frischtoxin unterlegen. Im Gegenteil stellt sie an den Antitoxingehalt des Serums höhere Ansprüche als die Prüfung mit Frischtoxin. Immerhin war es denkbar, da $B$ nun im Heilversuch sich das Verhältnis anders herausstellen und das mit Frischtoxin gewonnene Serum den Handelssera überlegen sein konnte. 
14 A. v. Wassermann und M. Ficker: Üher die Verwendung von frischem,

Ubber experimentelle Heilversuche beim Meerschweinchen mit Diphtherieserum sind in jüngster Zeit von Kolle und Schlossberger ${ }^{1}$ ) eingehende Untersuchungen veröffentlicht worden. Die genannten Autoren kommen dabei zu dem Schlusse, daß nur der Antitoxingehalt des Serums für die Heilwirkung bei Diphtherie eine Rolle spielt. Da Kolle und Schlossberger ihre Heilversuche auch mit einem Serum ausführten, das sie gemeinsam mit Dr. Joseph in den Höchster Farbwerken durch Immunisierung von Pferden mit lebenden Diphtheriebacillen gewonnen hatten, und sie bei diesem Serum keine Überlegenheit feststellen konnten, so sprach bereits dieser Umstand dagegen, daß das mit Frischtoxin gewonnene Antitoxin im Heilversuch eine im Vergleich mit dem bisherigen Diphtherieantitoxin überlegene Wirkung zeigen würde. Trotzdem haben wir der Vollständigkeit halber einige vergleichende Versuchsreihen auch über dic Heilwirkung der beiden verschieden hergestellten Antitoxine ausgeführt. Wie Kolle und Schlossberger bereits hervorgehoben haben, hängt die Feststellung des wirklichen Heilwertes eines Diphtherieserums im Tierexperiment von der Zeit ab, welche zwischen der Infektion mit Diphtheriebacillen und der Antitoxineinspritzung verflossen ist. Wenn diese Zeit mehr als etwa 6 Stunden beträgt, so ist eine Heilung nur noch mit spezifischem Antitoxin zu erreichen. Dementsprechend infizierten wir Meerschweinchen mit einer frischgezüchteten, in ihrer Virulenz genau geprüften lebenden Diphtheriekultur subcutan und injizierten einer Serie Versuchstiere 12 Stunden später das Höchster Handelsserum, einer anderen Serie das Serum Schwarzer. Das Höchster Serum war 400 fach gegen das Frankfurter Standardgift, das verwandte Serum Schwarzer war 500 fach gegen 100 tödliche Dosen Frischgift (siche obige Tab. VI).

Wie aus Tab. VIII ersichtlich ist, war das Serum Schwarzer in einer Menge von 3000 Immunitätseinheiten nach 12 Stunden wohl imstande, den Tod bei der Infektion mit $1 / 2$ oder $1 / 4$ Öse auf Löfflerserum gewachsener Diphtheriekultur stark hinauszuschieben, da die Kontrollen schon nach 2 Tagen an den gleichen Dosen starben, konnte aber den Exitus letalis nicht verhindern.

Nachfolgende Tab. IX, in welcher der gleiche Versuch 4 Tage später mit Serum Höchst ausgeführt wurde, ergab, daß 2400 Immunitätseinheiten dieses Serums 2 von 3 Tieren am Leben zu erhalten vermochten. Allerdings war die Kultur an dem mit dem Höchster Serum angestellten Versuchstage etwas weniger virulent, da die Kontrollen an der gleichen Dose erst am 5. bzw. 6. Tage starben. Aber selbst wenn man diesen Faktor berücksichtigt, ist er doch nicht genügend groß, um daraus irgendwie eine sichere Überlegenheit des mit Frischtoxin hergestellten Antitoxins gegenüber dem üblich, gewonnenen Diphtherieserum her-

1) 1. c. 
6. III. 1920.

Tabelle VIII.

Diphtherie-Heilversuch.

Kultur Di 41 (20stündig von Löfflerserum) in Bouillon susp. Vol. 0,5.

Di-Serum Schwarzer vom 14. II. 1920 nach 12 Stunden injiziert.

\begin{tabular}{|c|c|c|c|c|c|c|}
\hline $\begin{array}{l}\text { Meer- } \\
\text { sehw. } \\
2231 \mathrm{~g}\end{array}$ & $\begin{array}{l}\text { Kultur subc. } 9 \mathrm{~h} 90^{\circ} \text { abends } 6 \text {. III. } \\
\text { Serrum inp. } 10^{\mathrm{h}} \text { morgens } 7 \text {. III. }\end{array}$ & 8. III. & 9. III. & 10. III. & 11. II. & 12. III. \\
\hline $\begin{array}{l}106 \\
108 \\
110\end{array}$ & 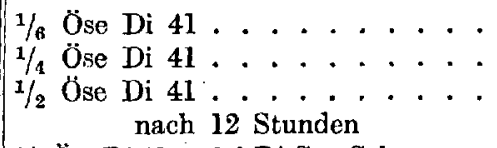 & $\begin{array}{l}\text { tot } \\
\text { tat } \\
\text { tot }\end{array}$ & & & & \\
\hline $\begin{array}{l}107 \\
109\end{array}$ & $\begin{array}{l}1 / 6 \text { Öse Di } 41+6,0 \text { Di-Ser. Schwarzer } \\
1 / 4 \text { Öse Di } 41+6,0 \text { Di Ser. Schwarzer }\end{array}$ & $\begin{array}{l}\text { g. ger. } \\
\text { Inf. } \\
\text { ger. }\end{array}$ & $\begin{array}{l}\text { ger. } \\
\text { Inf. } \\
\text { mäß. }\end{array}$ & f. o. B. & $\begin{array}{l}\text { weich. } \\
\text { Inf. } \\
\text { tot }\end{array}$ & $\begin{array}{c}\text { tot } \\
13 . / 14\end{array}$ \\
\hline 111 & $1 / 2$ Öse Di $41+6,0$ Di Ser. Schwarzer & $\begin{array}{l}\text { Inf. } \\
\text { tot }\end{array}$ & Inf. & & & \\
\hline
\end{tabular}

leiten zu können. Wir haben das „Frischtoxinserum“ dann noch auf der Diphtherieabteilung des Kaiserin Friedrich-Kinderkrankenhauses durch das liebenswürdige Entgegenkommen von Professor Finkelatein und auf der Diphtherieabteilung des Rudolph Virchow-Krankenhauses dank der Liebenswürdigkeit von Professor Dr. Ulrich Friedemann in einer Anzahl von Erkrankungsfällen anwenden lassen können, doch ließ sich nach den sehr sorgfältigen autoritativen Beobachtungen dieser beiden Herren ebenfalls keine Utberlegenheit feststellen.

10. IIT. 1920.

Tabelle IX.

Kultur Di 41 (20stïndig von Löfflerserum) mit Bouillon verd., Vol. 0,5. Di-Serum Höchst 500 fach nach 12 Stunden injiziert.

\begin{tabular}{|c|c|c|c|c|c|c|c|}
\hline $\begin{array}{l}\text { Meer- } \\
\text { schw. } \\
210 \mathrm{bis} \\
220 \mathrm{~g}\end{array}$ & $\begin{array}{l}\text { Kultur subcutan } 9^{\mathrm{H}} 30^{\circ} \\
\text { abends } 10 . \text { III. } \\
\text { Serum inp. 9h } 30^{\circ} \\
\text { morgens 11. III. }\end{array}$ & 12. III. & 13. III. & 15. III. & 16. XII. & 17. III. & 18. III. \\
\hline 113 & 1/a Öse Di 41 . . & st. Inf. & s. st. Inf. & - & tot & & \\
\hline 114 & $1 / 4$ Öse Di 41 . & st. Inf. & s. st. Inf. & - & tot & & \\
\hline 117 & $1 / 2$ Öse Di 41 & st. Inf. & $\begin{array}{l}\text { s. st. Inf. } \\
\text { krank }\end{array}$ & $\begin{array}{c}\text { krank } \\
\text { tot }\end{array}$ & & & \\
\hline 112 & $\begin{array}{l}\text { Serum nach } 12 \text { Std. } \\
1 / 8 \text { Öse Di } 41+6,0 \\
\text { Di Ser. Hö. }\end{array}$ & ger. Inf. & s. ger. Inf. & o. B. & o. B. & o. B. & tot \\
\hline 115 & $\begin{array}{l}1 / 4 \text { Öse Di } 41+6,0 \\
\text { Di Ser. Hö. }\end{array}$ & mäß. Inf. & $\begin{array}{l}\text { mäB. bis } \\
\text { ger. Inf. }\end{array}$ & o. $\mathrm{B}$. & a. B. & o. B. & o. B. \\
\hline 116 & $\begin{array}{l}\text { 1/2 Öse Di } 41+6,0 \\
\text { Di Ser. Hö. }\end{array}$ & mäB. Inf. & $\begin{array}{l}\text { mäß. bis } \\
\text { ger. Inf. }\end{array}$ & ger. Inf. & $\begin{array}{l}\text { ger. } \\
\text { Inf. }\end{array}$ & - & o. B. \\
\hline
\end{tabular}

Demgemäß kommen wir zu dem Schlusse, daß auch die jüngsten Diphtheriebacillengenerationen auf der Höhe ihrer Vitalität kein anderes Toxin als das bisher bekannte und zur Antitoxingewinnung verwendete 
produzieren, so daB sowohl die Antitoxinbereitung wie die von Ehrlich eingeführte Antitoxinbestimmung auch heute noch den strengsten Anforderungen genügt. Wir können auch durch das Arbeiten mit unabgebautem Frischtoxin keinerlei Anhaltspunkt dafür gewinnen, daß etwa bei der akuten Diphtherieerkrankung des Menschen qualitativ andere Toxine auftreten als in der Kultur, bezugsweise den bei der Diphtherieantitoxingewinnung bisher gebräuchlichen älteren Kulturgenerationen. Die Lehre von der spezifischen Therapie mit Diphtherieantitoxin besteht unerschüttert und ebenso der von Ehrlich geprägte Satz, daß die Achse jeder erfolgreichen spezifischen Diphtherietherapie das Diphtheriegift ist. Auch unsere Untersuchungen erwiesen wieder diese Achse als eine qualitativ einheitliche, ganz gleich, ob junges, unabgebautes oder älteres bis zur Konstanz abgelagertes Diphtherietoxin zur Verwendung kam. 